\title{
PENGETAHUAN MASYARAKAT DI DESA TOMBATU I KECAMATAN TOMBATU KABUPATEN MINAHASA TENGGARA TENTANG PENYAKIT MALARIA
}

\author{
${ }^{1}$ Patris J. Lombogia \\ ${ }^{2}$ Victor D. Pijoh \\ ${ }^{2}$ Greta J. P. Wahongan \\ ${ }^{2}$ Josef S. B. Tuda
}

\author{
${ }^{1}$ Kandidat Skripsi Fakultas Kedokteran Universitas Sam Ratulangi Manado \\ ${ }^{2}$ Bagian Parasitolgi Fakultas Kedokteran Universitas Sam Ratulangi Manado \\ E-mail: plombogia01@gmail.com
}

\begin{abstract}
Malaria is a very dominant infectious disease in the tropical and subtropical areas which can lead to death of more than a million people every year. Malaria is caused by infection of the protozoan parasite of the genus Plasmodium. Symptoms of malaria are not specific, such as headache, weakness, fatigue, abdominal discomfort, as well as muscle and joint pain, usually followed by fever, chills, sweating, anorexia, vomiting, and worsening malaise. Malaria control requires an integrated approach as follows: prevention (primary vector control) and immediate treatment with effective antimalarial drugs. This study aimed to determine the knowledge of malaria of villagers Tombatu I subdistrict Tombatu Southeast Minahasa District. This was a descriptive study with a cross-sectional design by using questionnaire. The study involved 95 respondents: 46 males (48.4\%) and 49 females (51.6\%). Ages of the majority were more than 41 years $(57.9 \%)$, most were high school educated (45.2 $\%$ ), and most were housewives (46.3\%). Resources of malaria were obtained from TV/ Electronic Media (66.7\%). Approximately 21\% respondents knew that the cause of malaria spreading was Anopheles species and as much as 50.9\% knew that mosquitoes bit at night. A total of $34.5 \%$ of respondents chose that puddles were breeding places of mosquitoes. A total of $42.2 \%$ of respondents knew that chills and fever were the symptoms of malaria. A total of $36.4 \%$ of respondents chose that the way of prevention was using mosquito nets. Conclusion: Knowledge about malaria transmission was good but about the species that caused malaria, the biting behavior of mosquitoes spreading malaria, and malaria breeding places was still poor.

Keywords: malaria, Anopheles mosquito species, knowledge of malaria.
\end{abstract}

\begin{abstract}
Abstrak: Malaria merupakan penyakit menular yang sangat dominan didaerah tropis dan subtropis yang dapat menyebabkan kematian lebih dari sejuta manusia setiap tahunnya. Malaria disebabkan oleh infeksi protozoa parasit dari genus Plasmodium. Gejala malaria yang tidak spesifik seperti sakit kepala, kelemahan, fatigue, ketidak nyamanan abdomen, dan nyeri otot dan sendi, biasanya diikuti oleh demam, menggigil, berkeringat, anoreksia, muntah dan malaise yang memburuk. Kontrol malaria membutuhkan pendekatan yang terintegrasi yaitu pencegahan (kontrol vektor primer) dan penanganan segera dengan antimalaria yang efektif. Penelitian ini bertujuan untuk mengetahui pengetahuan masyarakat Desa Tombatu I kecamatan Tombatu Kabupaten Minahasa Tenggara tentang malaria. Penelitian bersifat deskriptif survei desain potong lintang dengan menggunakan kuesioner. Penelitian melibatkan 95 responden yaitu 46 (48,4\%) laki-laki dan 49 (51,6 \%) perempuan, Usia terbanyak ialah lebih dari 41 tahun (57,9\%), pendidikan terbanyak SMA (45,2\%), dan pekerjaan terbanyak
\end{abstract}


ialah ibu rumah tangga (46,3\%). Sumber informasi malaria yang diperoleh responden dari TV/Media elektronik (66,7\%). Sekitar 21\% responden yang tahu spesies Anopheles penyebab penyebaran dan sebanyak 50,9\% mengetahui bahwa nyamuk menggigit pada malam hari. Sebanyak 34,5\% responden memilih bahwa genangan air pada tanah yang menjadi tempat perindukan nyamuk. Sebanyak $42 \%$ responden mengetahui bahwa panas menggigil merupakan gejala malaria. Sebanyak 36,4\% responden memilih cara pencegahan dengan menggunakan kelambu. Simpulan: Pengetahuan tentang malaria cukup baik tentang penularan malaria, namun pengetahuan tentang spesies penyebab malaria, perilaku menggigit nyamuk penyebar malaria, serta tempat perindukan malaria masih kurang.

Kata kunci: malaria, spesies nyamuk Anopheles, pengetahuan tentang malaria.

Malaria merupakan penyakit menular yang sangat dominan didaerah tropis dan subtropis yang dapat menyebabkan kematian lebih dari sejuta manusia setiap tahunnya. ${ }^{1}$ Di Indonesia penyakit ini masih merupakan masalah kesehatan yang multikompleks, sebab dapat meningkatkan kematian pada bayi, anak di bawah lima tahun dan ibu melahirkan., ${ }^{2,3}$

Malaria disebabkan oleh infeksi sel darah merah dengan protozoa parasit dari genus Plasmodium. Parasit berinokulasi ke dalam host manusia melalui nyamuk betina Anopeles. Terdapat empat spesies Plasmodium yang menginfeksi manusia yaitu $P$. falciparum, $P$. vivax, $P$. ovale dan $P$. malariae. Sementara itu terjadi peningkatan infeksi pada manusia dengan parasit malaria monyet yang dinamakan $P$. knowlesi, dilaporkan dari area perhutanan Asia Tenggara. ${ }^{4,5}$

Gejala pertama dari malaria adalah gejala-gejala yang tidak spesifik dan sama dengan gejala-gejala minor penyakti virus sistemik. Gejala-gejala tersebut seperti, sakit kepala, kelemahan, fatigue, ketidak nyamanan abdomen, dan nyeri otot dan sendi, biasanya diikuti oleh demam, menggigil, berkeringat, anoreksia, muntah dan malaise yang memburuk. Malaria dengan demikian, seringkali didiagnosa semata berbasis pada gejala-gejala itu sendiri, khususnya pada area-area endemik. Pada stadium awal, dengan tanpa ada bukti disfungsi organ tunggal, pasien dapat ditangani dengan penanganan yang menyediakan pemulihan yang cepat dan efektif. Jika obat yang diberikan tidak efektif atau jika penanganan ditunda khususnya pada malaria P. falciparum, beban paraasit akan mengalami peningkatan lanjut dan malaria berat dapat terjadi. Progresifitas infeksi malaria dapat terjadi dalam beberapa jam. ${ }^{1,4}$

Penyakit malaria di Indonesia sampai saat ini masih merupakan masalah kesehatan masyarakat. Prevalensi nasional Malaria 2007 (berdasarkan diagnosis tenaga kesehatan dan keluhan responden) adalah 2,85\%. Sebanyak 15 provinsi mempunyai prevalensi Malaria diatas prevalensi nasional, yaitu Nanggroe Aceh Darussalam, Sumatera Utara, Jambi, Bengkulu, Bangka Belitung, Nusa Tenggara Barat, Nusa Tenggara Timur, Kalimantan Barat, Kalimantan Tengah, Sulawesi Tengah, Gorontalo, Maluku, Maluku Utara, Papua Barat, dan Papua. ${ }^{2}$ Di Provinsi Sulawesi Utara (2008), jumlah penderita malaria klinis tidak mempunyai pola yang tetap, namun jumlah kasus malaria klinis pertahun selama empat tahun terakhir berkisar pada angka 30.000 kasus. Sedangkan prevalensi penyakit malaria di Kecamatan Tombatu Kabupaten Minahasa Tenggara pada tahun 2013 berjumlah 482 kasus. $^{6}$

Kontrol malaria membutuhkan pendekatan yang terintegrasi termasuk pencegahan (kontrol vektor primer) dan penanganan segera dengan antimalaria yang efektif. Sejak publikasi edisi pertama panduan penanganan malaria oleh WHO pada tahun 2006, kebanyakan dari negaranegara dimana $P$. falciparum sebagai penyebab utama dan telah resisten terhadap 
preparat chloroquine (CQ) dan sulfadoxinepyrimethamine (SP), telah mengganti regimen pengobatan menggunakan preparat artemisinin berbasis terapi kombinasi (ACT). Hal tersebut merupakan penanganan terbaik malaria falsifarum tanpa komplikasi saat ini. Kebijakan pemakaian sediaan ACT sekarang telah ditinggalkan karena berbagai faktor seperti biaya yang tinggi dan efek samping obat terhadap penderita, oleh karena itu perlu upaya pencegahan yang komprehensif. Salah satu faktor yang mempengaruhi dalam pencegahan penyakit malaria diantaranya adalah perilaku seseorang dalam bentuk pengetahuan, sikap dan praktik. ${ }^{4,7}$

Pengetahuan masyarakat tentang malaria meliputi bagaimana pola penularan, pencegahan dan pengobatan malaria sangat penting dalam usaha pencegahan dan pengendalian penyakit malaria, oleh karena itu penulis merasa perlu untuk melakukan penelitian di Desa Tombatu I Kecamatan Tombatu sebagai daerah endemis malaria tentang gambaran pengetahuan masyarakat terhadap penyakit malaria.

\section{METODE PENELITIAN}

Penelitian ini merupakan penelitian deskriptif survei potong lintang dengan menggunakan kuesioner. Populasi yang diambil dalam penelitian ini adalah semua masyarakat Desa Tombatu I Kecamatan Tombatu. Sampel dipilih berdasarkan rumus Slovin berjumlah 95 responden. Data diperoleh dengan cara wawancara langsung dengan setiap rumah tangga diwakili 1 orang, dengan menggunakan kuesioner. penelitian diuraikan dalam bentuk tabel penelitian dan dianalisis berdasarkan persentase.

\section{HASIL PENELITIAN DAN BAHASAN}

Responden perempuan lebih banyak berperan dalam penelitian ini 51,6\%, dengan usia terbanyak lebih dari 41 tahun yaitu sebesar $57,9 \%$, pendidikan terbanyak ialah SMA sebesar 45,2\%, dan pekerjaan terbanyak dari responden ialah ibu rumah tangga yaitu sebesar 46,3\%. Mengenai penerimaan informasi tentang malaria, hampir semua responden telah mengetahui tentang malaria, sumber informasi yang diperoleh dari TV/Media elektronik sebesar 66,7\%. Media elektronik seperti radio atau televisi bisa menjadi alternatif yang dapat digunakan untuk menyebarkan informasi tentang masalah kesehatan terutama malaria. Hampir setiap rumah memiliki televisi atau radio dan kebanyakan waktu yang ada dihabiskan di depan televisi.

Semua responden tahu bahwa malaria ditularkan melalui gigitan nyamuk, namun pada bagian kedua hanya 21\% yang tahu spesies nyamuk penyebar malaria adalah spesies Anopheles. Pengetahuan jenis nyamuk juga memengaruhi pengetahuan mengenai perilaku menggigit nyamuk. Ditemukan 50,9\% responden yang mengetahui bahwa nyamuk menggigit pada malam hari.

Sebagian besar responden memilih bahwa genangan air pada tanah yang menjadi tempat perindukan nyamuk (34,5\%), diikuti oleh rawa sebesar 34,1\%. Gejala malaria yang khas mudah diketahui, namun bila disertai dengan infeksi sekunder, gejala khas malaria bisa tertutupi sehingga dianggap bukan malaria. Pada penelitian ini, semua responden menjawab ya pada pengetahuan gejala dan tanda penyakit malaria, dengan 42,2\% mengetahui bahwa panas menggigil adalah gejala malaria.

Sebanyak 96,8\% responden mengetahui cara pencegahan malaria. Pada bagian kedua sebanyak 36,4\% responden memilih cara pencegahan dengan menggunakan kelambu. 
Lombogia, Pijoh, Wahongan, Tuda: Pengetahuan masyarakat di desa Tombatu I...

Tabel 1. Distribusi berdasarkan jenis kelamin, usia, pendidikan, pekerjaan

\begin{tabular}{llcc}
\hline Jenis kelamin & Laki-laki & 46 & $48,4 \%$ \\
& Perempuan & 49 & $51,6 \%$ \\
& Jumlah & $\mathbf{9 5}$ & $\mathbf{1 0 0} \%$ \\
\hline Usia & Kurang dari 25 tahun & 4 & $4,2 \%$ \\
& 26-40 tahun & 36 & $37,9 \%$ \\
& Lebih dari 41 tahun & 55 & $57,9 \%$ \\
& Jumlah & $\mathbf{9 5}$ & $\mathbf{1 0 0} \%$ \\
\hline Pendidikan & SD & 24 & $25,3 \%$ \\
& SMP & 26 & $27,4 \%$ \\
& SMA & 43 & $45,2 \%$ \\
& Sarjana & 2 & $2,1 \%$ \\
& Jumlah & $\mathbf{9 5}$ & $\mathbf{1 0 0} \%$ \\
\hline Pekerjaan & Pegawai Swasta & 3 & $3,2 \%$ \\
& Wiraswasta & 9 & $9,5 \%$ \\
& Petani & 33 & $34,7 \%$ \\
& Buruh & 6 & $6,3 \%$ \\
& Ibu rumah tangga & 44 & $46,3 \%$ \\
& Jumlah & $\mathbf{9 5}$ & $\mathbf{1 0 0} \%$ \\
\hline
\end{tabular}

Tabel 2. Distribusi responden berdasarkan penerimaan informasi tentang malaria

\begin{tabular}{|c|c|c|}
\hline & Jumlah & $\%$ \\
\hline \multicolumn{3}{|l|}{ Informasi tentang malaria } \\
\hline a. Ya & 95 & 100 \\
\hline b. Tidak & 0 & 0 \\
\hline \multicolumn{3}{|l|}{ Sumber informasi } \\
\hline a. TV/Media elektronik & 74 & 66,7 \\
\hline b. Koran & 9 & 8,1 \\
\hline c. Penyuluhan & 16 & 14,4 \\
\hline d. Lain-lain & 12 & 10,8 \\
\hline Jumlah & 111 & 100 \\
\hline
\end{tabular}

Tabel 3. Distribusi responden berdasarkan pengetahuan vektor penyebaran malaria

\begin{tabular}{ccc}
\hline & Jumlah & \% \\
\hline Melalui gigitan nyamuk & & \\
a. Ya & 95 & 100 \\
b. Tidak & 0 & 0 \\
\hline
\end{tabular}

Tabel 4. Distribusi responden berdasarkan pengetahuan perilaku menggigit nyamuk

\begin{tabular}{ccc}
\hline $\begin{array}{l}\text { Perilaku } \\
\text { mengigit }\end{array}$ & Jumlah & $\mathbf{\%}$ \\
\hline a. Pagi & 11 & 10,8 \\
b. Siang & 39 & 38,3 \\
c. Malam & 52 & 50,9 \\
Jumlah & $\mathbf{1 0 2}$ & $\mathbf{1 0 0}$ \\
\hline
\end{tabular}

Tabel 5. Distribusi responden berdasarkan pengetahuan perindukan nyamuk

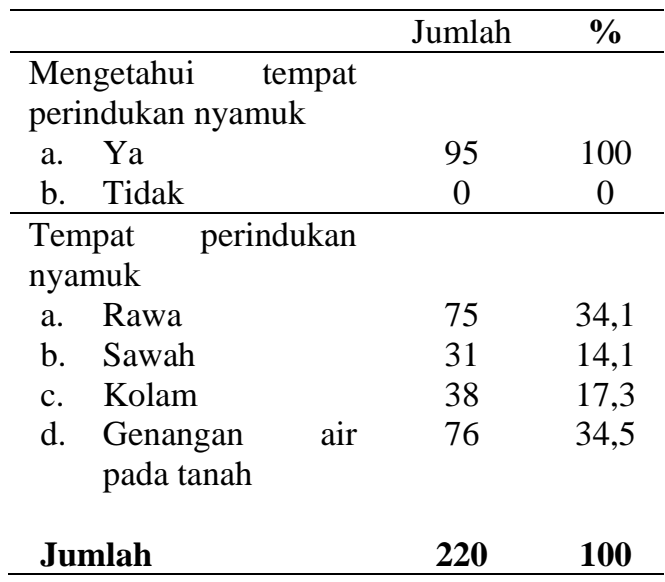

Tabel 6. Distribusi responden terhadap pengetahuan gejala dan tanda penyakit malaria

\begin{tabular}{|c|c|c|}
\hline & Jumlah & $\%$ \\
\hline \multicolumn{3}{|l|}{ Mengetahui tanda dan gejala } \\
\hline a. Ya & 95 & 100 \\
\hline b. Tidak & 0 & 0 \\
\hline \multicolumn{3}{|l|}{ Gejala } \\
\hline a. Panas menggigil & 94 & 42,1 \\
\hline $\begin{array}{l}\text { b. Sakit kepala berat dan terus } \\
\text { menerus }\end{array}$ & 49 & 21,9 \\
\hline c. Mual dan disertai muntah & 32 & 14,4 \\
\hline d. Badan lemah dan pucat & 48 & 21,6 \\
\hline Jumlah & 223 & 100 \\
\hline
\end{tabular}


Tabel 7. Distribusi responden terhadap pengetahuan pencegahan penyakit malaria

\begin{tabular}{lcc}
\hline & Jumlah & $\mathbf{\%}$ \\
\hline $\begin{array}{l}\text { Pengetahuan pencegahan } \\
\text { a. Ya }\end{array}$ & 92 & 96,8 \\
b. Tidak & 3 & 3,2 \\
Jumlah & $\mathbf{9 5}$ & $\mathbf{1 0 0}$ \\
\hline $\begin{array}{l}\text { Cara pencegahan } \\
\text { a. Menggunakan kelambu }\end{array}$ & 85 & 36,4 \\
b. Obat pembasmi pada & 62 & 26,5 \\
$\quad$ malam hari & & \\
c. Menggunakan repelen & 41 & 17,5 \\
d. Tidak beaktifitas diluar & 46 & 19,6 \\
$\quad$ pada malam hari & & \\
Jumlah & $\mathbf{2 3 4}$ & $\mathbf{1 0 0}$ \\
\hline
\end{tabular}

\section{SIMPULAN}

Pengetahuan masyarakat Desa

Tombatu I Kecamatan Tombatu Kabupaten Minahasa Tenggara tentang malaria pada beberapa hal cukup besar yaitu tentang penularan malaria, namun pada hal-hal penting tentang spesies penyebab malaria, perilaku menggigit nyamuk penyebar malaria, serta tempat perindukan malaria, masih kurang.

\section{SARAN}

Dari hasil penelitian tersebut dapat dikatakan bahwa pengetahuan masyarakat tentang pencegahan penyakit malaria masih kurang sehingga perlu ditingkatkan dengan penyuluhan secara berkala. Masyarakat perlu diedukasi terus menerus sehingga angka kejadian malaria dapat ditekan serendah mungkin.

\section{DAFTAR PUSTAKA}

1. CDC. Center for Disease Control and Prevention. [Online].; 2013 [cited 2014 September 26. Available from: http://www.cdc.gov/malaria/resource s/pdf/treatmenttable.pdf" http://www.cdc.gov/malaria/resource s/pdf/treatmenttable.pdf .

2. Riset Kesehatan Dasar (RISKESDAS) 2007. Laporan nasional 2007; 2008.

3. Veridiana NN, Chadijah S, Srikandi Y, Octaviani. Konfirmasi vektor malaria dengan Elisa di daerah Mendui, kec. Bungku Tengah, kab. Morowali, Sulawesi Tengah. Jurnal Vektor Penyakit. 2009 Juni; III(1): p. 25-31.

4. WHO. Guideline for the treatment of malaria-second edition, 2010.

5. Bell D. Malaria diagnosis, WHO guidelines and their implementation. World Health Organization, European Commission Research Workshop, 2010

6. Dinas Kesehatan Provinsi Sulawesi utara. Profil kesehatan provinsi Sulawesi Utara 2008. ; 2009.

7. National Vector Borne Disease Control Programme Delhi. Guidelines for diagnosis and treatment of malaria in India. National Institute of Malaria Research New Dehli; 2011. 